\title{
Enfermedad boca-mano-pie: ¿la nueva «gran imitadora»?
}

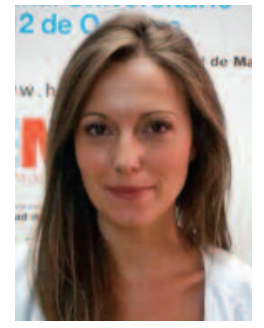

Lidia Maroñas-Jiménez Facultativo especialista de área.

Servicio de Dermatología. Hospital Universitario 12 de Octubre. Madrid. Instituto de Investigación i+12.

Universidad Complutense. Madrid.
La enfermedad boca-mano-pie (EBMP) fue descrita por los autores clásicos como una enfermedad exantemática benigna de la infancia asociada a la infección por el virus Coxsackie A16 ${ }^{1-3}$. Con unas características clínicas y epidemiológicas muy distintivas, su identificación en consulta ha supuesto uno de los diagnósticos diferenciales tradicionalmente más agradecidos para dermatólogos y pediatras.

Desde finales del año 2008, estamos asistiendo a la emergencia de lo que podría considerarse una nueva variante de enfermedad exantemática ligada a enterovirus, que ha sido denominada enfermedad bocamano-pie atípica (EBMPA), por su cierta analogía con la entidad clásica. No obstante, el amplio espectro de enterovirus implicados, su especial predilección por la población adulta y, sobre todo, su sorprendente polimorfismo y capacidad de simulación clínica en relación con las manifestaciones cutáneas distan considerablemente de lo que todos habíamos entendido hasta ahora como EBMP, al menos, desde un punto de vista académico. Por lo tanto, ¿debemos bautizar a la clásica EBMP como la «gran imitadora» del siglo XXI? o ¿realmente nos encontramos ante una nueva expresión de infección por enterovirus cuyas características clínicas, epidemiológicas y micro- biológicas están aún por definir? Probablemente, todavía sea demasiado pronto para poder dar una respuesta firme al respecto.

\section{ENFERMEDAD BOCA-MANO-PIE CLÁSICA}

Las primeras referencias de esta enfermedad datan de 1957, momento en que Robinson et al. describieron una epidemia de estomatitis vesicular asociada a un exantema en manos y pies de similares características en un grupo de niños canadienses en los que se aisló el virus Coxsackie A16. Sin embargo, no fue hasta dos años más tarde cuando Alsop et al. recurrieron el término de EBMP para describir una segunda epidemia de idéntica expresividad clínica en Inglaterra ${ }^{4}$.

La resistencia a los disolventes orgánicos y la fácil transmisibilidad por vía fecal-oral de los virus Coxsackie favorecen que la enfermedad suela aparecer de forma epidémica durante los meses más calurosos del año, asociada casi exclusivamente al virus Coxsackie A16 o a su genéticamente correlacionado enterovirus $71^{1-4}$. Ocasionalmente, se han descrito casos aislados o pequeños brotes ligados a otros serotipos de Coxsackie A y B.

Si bien es cierto que existen notificaciones esporádicas de EBMP clá- 
sica en adolescentes y adultos jóvenes, los niños de entre 1 y 7 años suponen el principal grupo poblacional afectado. Tras un período de incubación que puede variar entre 3 y 6 días, suele acontecer un cuadro inespecífico de síntomas prodrómicos (febrícula, malestar general, diarrea o dolor abdominal), que anuncia la aparición de las lesiones típicas en la boca, las manos y los pies durante las 12-24 horas siguientes. Con distinta intensidad, pero de forma constante, todos los pacientes desarrollan lesiones en la mucosa oral, que tienden a localizarse, predominantemente, en el paladar duro, la lengua y la mucosa yugal. De forma concomitante o poco después, aparecen las lesiones cutáneas acrales, comúnmente dispuestas sobre el dorso y las caras laterales de manos y pies. Aunque la curiosa distribución «en mano-pie-boca» otorga el nombre de la enfermedad, las características morfológicas de las lesiones cutáneo-mucosas son, sin duda, otra de sus señas de identidad. Tanto el enantema como la erupción cutánea se inician en forma de pequeñas pápulas, que evolucionan a vesículas de coloración blanco-grisácea, rodeadas por un halo de eritema. Eventualmente, las vesículas orales se rompen, dejando ulceraciones que pueden simular una estomatitis aftosa, lo cual es anecdótico a nivel cutáneo. De forma ocasional, se observa un exantema maculopapuloso limitado a las nalgas o los glúteos, que, excepcionalmente, puede generalizarse.

Dado que tanto las manifestaciones dermatológicas como la posible clínica general acompañante suelen resolverse de forma espontánea en el transcurso de 7 a 10 días, el tratamiento únicamente va dirigido a paliar los síntomas. Las complicaciones sistémicas son excepcionales, aunque se han descrito casos raros de meningoencefalitis, parálisis motora y miocarditis.

El diagnóstico de la enfermedad es eminentemente clínico, y se basa en la identificación del cuadro dermatológico típico asociado a un antecedente epidemiológico relevante.

\section{ENFERMEDAD BOCA-MANO-PIE ATÍPICA}

Posiblemente, el brote nacional de EBMP asociado a onicomadesis que ocurrió en Finlandia durante los meses de otoño de 2008 y 2009 marcó un punto de inflexión en la historia de esta enfermedad. Hasta ese momento, las epidemias de EBMP se habían caracterizado por presentar un cuadro cutáneo distintivo y estar asociadas de forma invariable a dos tipos de enterovirus, el virus Coxsackie A16 y el enterovirus 71. Österback $e t$ $a l$. fueron los primeros en demostrar la implicación de una nueva cepa de enterovirus en la EBMP epidémica, tras aislar el virus Coxsackie A6 de las lesiones cutáneas de dos niños y un adulto que resultaron afectados durante el brote de Finlandia de 2008-20095 . Asimismo, postularon la importancia creciente de este virus - tradicionalmente, implicado en casos de herpangina- en una EBMP emergente de características clínicas y epidemiológicas peculiares. A partir de entonces, se han notificado múltiples brotes de EBMP de rasgos inusuales, tanto a nivel internacional como en España, donde existe constatación microbiológica del predominio de esta nueva variante desde finales del año $2010^{6,7}$.

¿Y qué peculiaridades tienen estos brotes de EBMP para catalogarlos como atípicos? La bibliografía recoge una mayor afectación de adultos, predominio de la enfermedad en los meses más fríos del año y, especialmente, un amplio espectro de manifestaciones clínicas, con formas cutáneas más extensas, de distribución inesperada y de características morfológicas muy variables, que pueden simular desde una varicela, un impétigo o una enfermedad ampollosa autoinmunitaria hasta una vasculitis o una endocarditis, planteando serios problemas de diagnóstico diferencial.

En un intento por categorizar el gran polimorfismo clínico cutáneo de esta nueva variante exantemática, Mathes et al. realizaron un estudio retrospectivo multicéntrico del brote norteamericano de EBMPA ocasionado por el virus Coxsackie A6 
entre 2011 y $2012^{8}$. Para ello, revisaron las características epidemiológicas y las peculiaridades cutáneo-mucosas de los casos clínica o microbiológicamente predefinidos como EBMPA, que fueron atendidos en siete servicios de dermatología pediátrica de Estados Unidos entre julio de 2011 y junio de 2012. Incluyeron un total de 80 pacientes (edad media: 1,5 años; intervalo: 4 meses-16 años), 63 con criterios clínicos para EBMPA y 17 con resultado positivo para el virus Coxsackie A6. Globalmente, observaron que, en el $61 \%$ de los pacientes, el exantema afectaba a más del $10 \%$ de la superficie corporal, distribuyéndose frecuentemente por las extremidades, el tronco y la región peribucal. Es importante señalar que propusieron cuatro variantes clínicas vinculadas a la emergente EBMPA:

1. Forma vesículo-costrosa de tipo impetiginoso: mayoritaria en su serie, al estar presente en el $46 \%$ de los niños.

2. Forma papulosa tipo Gianotti-Crosti: definida en el $37 \%$ de los niños.

3. Forma purpúrico-petequial: minoritaria en su estudio (17\%), pero significativamente más común en los niños mayores de los 5 años de edad.

4. Eccema coxsackium: por analogía al eccema herpético, los autores acuñaron este término para definir la llamativa tendencia del exantema a localizarse sobre áreas previamente afectas de dermatitis, escenario clínico que fue descrito en el $55 \%$ de los pacientes.

Tras la publicación de Mathes $e t a l .^{8}$, se han comunicado brotes de EBMPA de características clínicas compatibles con lo descrito por estos autores prácticamente en todo el mundo ${ }^{9,10}$. Si bien la mayoría de estos han sido atribuidos a epidemias por Coxsackie A6, diversos enterovirus distintos a este y a los tradicionales Coxsackie A16 y enterovirus 71 también se han observado en brotes de enfermedad atípica. De ahí que la mayor parte de los autores prefiera concebir la denomi- nada EBMPA como un nuevo síndrome exantemático emergente ligado a la infección por enterovirus.

\section{NUESTRA EXPERIENCIA EN EL HOSPITAL 12 DE OCTUBRE}

La mayor parte de la literatura médica publicada se ha centrado en definir las manifestaciones clínicas de la EBMPA en los niños, existiendo muy poca bibliografía al respecto de su expresión en adultos, pese haberse descrito una mayor tasa de ataque en población de más edad. Basándonos en la emergencia de casos de EBMPA, nos propusimos categorizar clínicamente los casos que acudieron al servicio de urgencias de nuestro hospital entre mayo de 2012 y mayo de 2013, identificando las posibles diferencias entre niños y adultos. Para ello, realizamos un estudio prospectivo reclutando pacientes con exantemas de predominio acral, sintomatología prodrómica y una historia de exposición a EBMP entre los 2 y los 14 días previos al inicio del cuadro. Aquellos pacientes con EBMP típica, hallazgos clínicos o evidencia microbiológica consistente con otra dermatosis específica fueron excluidos. Obtuvimos un total de 19 pacientes de edades comprendidas entre los 2 y los 36 años de edad, distribuidos de forma aproximadamente equitativa entre niños y adultos y un ligero predominio masculino, especialmente, en el grupo pediátrico. La mayoría de los casos se agruparon desde finales de 2012 hasta principios de 2013, coincidiendo con los meses más fríos del período, y presentaron un cuadro pseudogripal autolimitado como principal sintomatología prodrómica. Pudimos observar las tres formas clínicas previamente descritas por Mathes et al., siendo la purpúrico-petequial la variante morfológica de exantema predominante, probablemente, debido a la mayor proporción de adultos recogida en nuestra serie (fig. 1). Le siguieron en frecuencia el exantema papuloso (fig. 2) y el erosivo-costroso (fig. 3), los cuales mostraron significativamente más afectación crural y perioral. Ninguno de los casos recogidos presentó carac- 

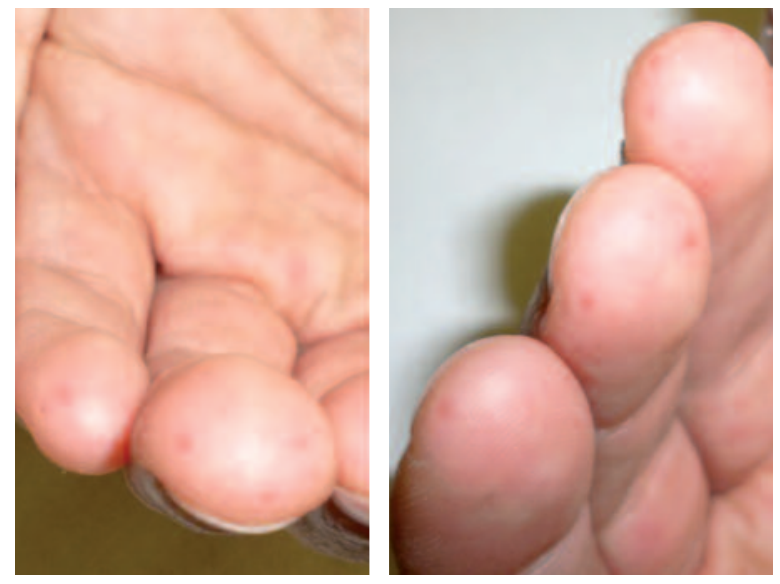

Figura 1. Detalle clínico de la variante purpúrica en un varón adulto que presentaba lesiones petequiales lanceoladas en manos y pies.

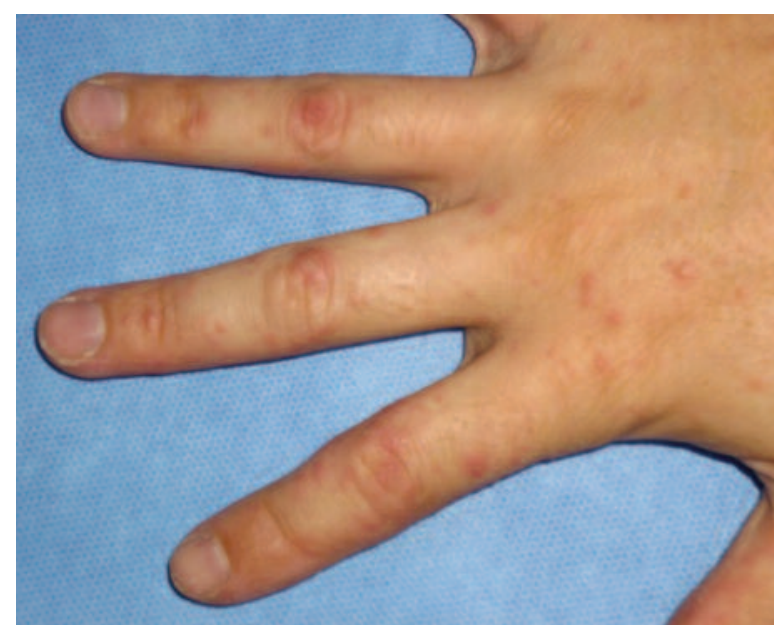

Figura 2. Pápulas eritematosas monomorfas en las manos de un adulto con enfermedad boca-mano-pie atípica.

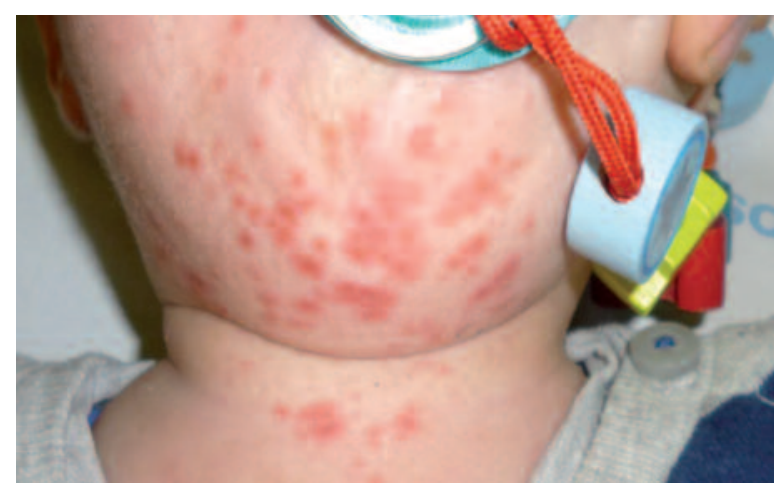

Figura 3. Lesiones erosivo-costrosas exudativas en la región peribucal de un niño diagnosticado erróneamente de impétigo.

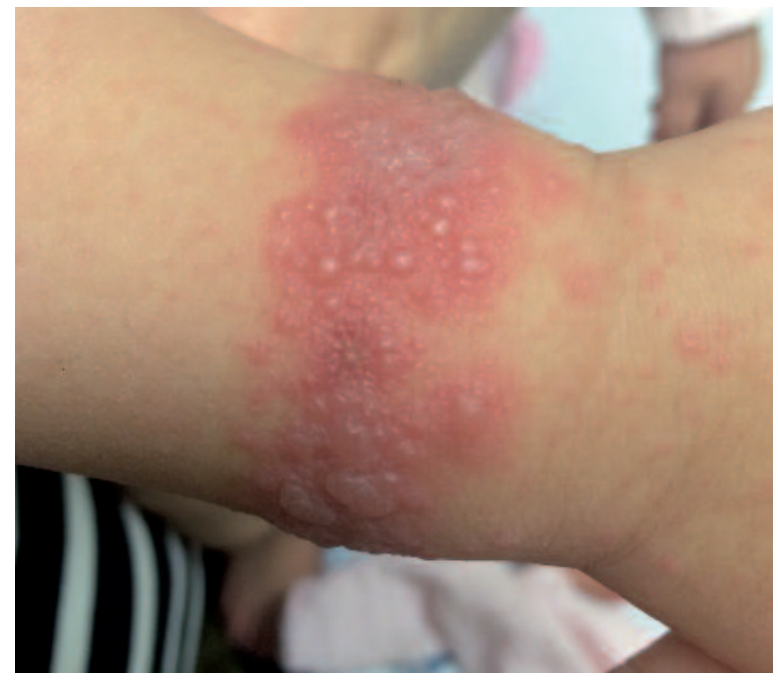

Figura 4. Lesiones vesículo-ampollosas sobre un área eccematosa en un niño con enfermedad boca-mano-pie y dermatitis atópica.

terísticas compatibles con la definición de eccema coxsackium, variante que hemos podido observar posteriormente en consultas (fig. 4).

Una novedad importante de nuestro estudio es que halló diferencias en relación con la expresión clínica del exantema según la edad. De forma significativa, la variante morfológica más frecuentemente observada en los niños fue el exantema erosivo-costroso, mientras que, en los adultos, predominaron las formas purpúrico-petequiales. Asimismo, el porcentaje de superficie corporal total afectada fue significativamente mayor en la población pediátrica, mientras que la sintomatología local (prurito) fue predominante en el grupo de los adultos.

Aunque los resultados completos se encuentran actualmente en vías de publicación, este adelanto nos sirve para recalcar el concepto de que existen formas definidas, pero clínicamente muy alejadas de la clásica EBMP, asociadas a la infección por enterovirus que debemos considerar en el diagnóstico diferencial de la patología exantemática tanto de niños como de adultos. Nuestra destreza clínica a la hora de identificar nuevos casos de esta emergente entidad debe contemplar su variable expresividad morfológica según la edad. 


\section{BIBLIOGRAFÍA}

1. Robinson CR, Doane FW, Rhodes AJ. Report of an outbreak of febrile illness with pharyngeal lesions and exanthem: Toronto, summer 1957; isolation of group A Coxsackie virus. Can Med Assoc J. 1958;79(8):615-21.

2. Cherry JD, Jahn CL. Hand, foot, and mouth syndrome. Report of six cases due to coxsackie virus, group A, type 16. Pediatrics. 1966;37(4):637-43.

3. Lerner AM, Klein JO, Cherry JD, Finland M. New viral exanthems. N Engl J Med. 1963;269:678-85.

4. Martínez Estrada V, Laureano Lazcano M. Enfermedad manopie-boca. Presentación de un caso y breve revisión de la literatura. Rev Cent Dermatol Pascua. 1999;8(1):21-4.

5. Osterback R, Vuorinen T, Linna M, Susi P, Hyypiä T, Waris M. Coxsackievirus A6 and hand, foot, and mouth disease, Finland. Emerg Infect Dis. 2009;15(9):1485-8.

6. Montes M, Artieda J, Piñeiro LD, Gastesi M, Diez-Nieves I, Cilla G. Hand, foot, and mouth disease outbreak and cox- sackievirus A6, northern Spain, 2011. Emerg Infect Dis. 2013; 19(4).

7. Cabrerizo M, Tarragó D, Muñoz-Almagro C, Del Amo E, Domínguez-Gil M, Eiros JM, et al. Molecular epidemiology of enterovirus 71, coxsackievirus A16 and A6 associated with hand, foot and mouth disease in Spain. Clin Microbiol Infect. 2014;20(3):0150-6.

8. Mathes EF, Oza V, Frieden IJ, Cordoro KM, Yagi S, Howard R, et al. "Eczema coxsackium" and unusual cutaneous findings in an enterovirus outbreak. Pediatrics. 2013;132(1):e14957.

9. Feder HM Jr, Bennett N, Modlin JF. Atypical hand, foot, and mouth disease: a vesiculobullous eruption caused by Coxsackie virus A6. Lancet Infect Dis. 2014;14(1):83-6.

10. Sinclair C, Gaunt E, Simmonds P, Broomfield D, Nwafor N, Wellington $L$, et al. Atypical hand, foot, and mouth disease associated with coxsackievirus A6 infection, Edinburgh, United Kingdom, January to February 2014. Euro Surveill. 2014; 19(12):20745. 